\title{
Analysis and Research on the Modern University Classroom Teaching Quality Evaluation System
} ZhenYu Qiu, Shuhua Bai , Haidong Yang

\author{
Nanchang Institute of Technology, Nanchang, Jiangxi 330044, China
}

Keywords: College, Classroom Teaching, Evaluation System, Analysis and Research.

\begin{abstract}
The classroom teaching evaluation system is one of the main teaching contents of the polytechnic major of colleges and universities, and it is an important practical teaching link throughout the whole teaching process. It plays an important and irreplaceable role in cultivating students' theoretical connection and realizing the goals of education and innovative talent cultivation. Modern teaching reform pays attention to the cultivation of the ability of innovation and solving practical problems according to the "knowledge + ability + quality" mode. This is because the training of talents cannot be separated from practice. It is only through practice that the quality of talents can meet the social needs. With the further development of teaching reform, to carry out the research on classroom teaching evaluation system of quality evaluation system, promote the construction of the classroom teaching evaluation system, reform and development, improve the quality of classroom teaching evaluation system and develop the students' scientific quality and innovation ability is of great significance.
\end{abstract}

\section{Introduction}

Computer science knowledge update quickly, new technologies, new techniques, new devices, new software is constantly emerging, such as the local colleges restricted by educational condition, lagging teaching content, teaching mode of the single, rigid teaching method, experiment equipment is old, the phenomenon such as \"heavy theory, light practicel".This not only hinder the innovative consciousness and innovative ability of students, also unfavorable to the cultivation of talents. Therefore, as the local colleges and universities to improve the practice teaching level, training students' practical ability and innovation ability, must according to their own actual, to explore their own way. Experiment from its essence is a kind of innovation activities, it is under the guidance of scientific thought, according to certain conditions using the technology to explore unknown or verify the hypothesis of practice. Classroom teaching evaluation system is different from both theoretical teaching and also different from general scientific research. Its mission is not only let the student through the experiment to verify and deepen our understanding of knowledge, but more important is to let students grasp scientific research methods and set up the scientific spirit of innovation, bold design new methods to solve practical problems, to cultivate the ability to explore the unknown, innovative consciousness and creative ability. Only correctly recognize this, design training plan, training objectives, to pass the classroom teaching evaluation system is an important carrier to achieve the purpose of quality education and innovation education.

In recent years, the development of colleges and universities has been very rapid, and the teaching and construction of classroom teaching has been greatly improved. How to evaluate investment efficiency, how to give full play to the classroom teaching in the aspects such as personnel training, scientific research and social service, further enhance the vitality of the classroom teaching, optimize the allocation of resources, realize the resource sharing, improve the quality of classroom teaching and the scientific research level, we will substantially raise the overall efficiency of classroom teaching, to become the classroom teaching in colleges and universities and the equipment management department of the important research topic. To make scientific evaluation system of classroom teaching quality, the 
assessment system results from an investment class teaching organically, to promote the effective means of improving the teaching quality in colleges and universities.

\section{Improve the Innovation Ability and Practical Ability of Computer Science Students through Quality Evaluation System}

The new technology lecture plays an important role in enriching students' extracurricular life, expanding their horizons and broadening their knowledge. To this end, our hospital held a series of special lectures, shall be borne by the various teaching and research section, but also invited companies such as huawei, aptech top management for the students to do project development and management of the seminar. Let students keep abreast of industry trends and track the latest research in the IT field. At the same time, through these lectures, teachers have deepened their communication with students, expanded their influence, and created favorable conditions for follow-up project groups and research group activities.

In recent years, colleges and universities of undergraduate course graduation design has many problems, such as the old thesis topic selection, the choice surface is narrow, such as student management system, library management system, the information such as laboratory equipment management system management system such as the title of the a share, and every year in repeated use. Some employers and enterprises reflect the lack of practical ability and experience in programming and development of computer science graduates. The main reason is that students lack of engineering practice experience, such as in software design and production, students are still stay in realize the algorithm of character under the interface problems with the language, unable to develop a graphical interface application system. There are fewer students who can do the research on the hardware, and there are only the design principles on the structural level, which can't be connected with the actual situation. Therefore, the training and guidance of engineering practice is indispensable to improve the practice ability of undergraduates. The development group aims to strengthen students' professional knowledge, cultivate students' engineering quality and teamwork spirit, and alleviate the contradiction between theoretical knowledge and engineering practice. The members mainly focus on the senior students, to guide the teacher's actual project or virtual project as the project, and to study independently under the guidance and training of teachers. Encourage and introduce students to the program. It is shown that the setting of the project team has greatly changed the students' theoretical foundation and weak ability.

\section{By Evaluating the Feedback of the System, We Adopt the Scientific Teaching Mode to Train Students' Innovation Ability}

In the process of teaching, the teacher should guide students step by step to master the methods to solve the problem, let the student directly involved in the teaching, give full play to students' subjective initiative, develop the innovative ability of students, make students in learning a sense of accomplishment, it helps cultivate their set scientific attitude and mastering scientific method. "The most effective way to learn is to let students learn in the process of experience and creation." Use computer multimedia, big screen projection, network and other advanced education methods instead of traditional chalk and blackboard. In class, I focus on the problem of creating, provide atmosphere, let the students find problems in the practice, and set out to solve the problem, so as to become the master of learning, teachers become students "collaborators". For example, in explaining word design, let students familiarize themselves with the word interface, learn the functions of each menu item, and help students learn to use the help menu. When students start to learn the software, they feel a lot of difficulties, and every few steps will encounter new problems and even conflict. At this time, as a teacher will patiently to guide and encourage students to discover new problems, and guide students to boldly experiment, and provides the feasible processing method, so that the students in the operation summed up the regularity of the method to solve the problem. 


\section{In Order to Improve Students' Ability of Employment and Innovation, We Should Optimize Practical Teaching}

College of education objectives, requirements to improve students' ability to apply the knowledge for solving the problems, and strengthen the practice teaching, fully embody the highlight the characteristics of higher vocational colleges, so as to play to the advantages of higher vocational colleges. To this end, we should strengthen the design of practical training and practice, as well as the construction of classroom teaching and training platform. It is necessary for students to participate in practice and research activities based on the teaching of wide - caliber subject and to carry out overall design and practical implementation of the teaching content system of practice. Practical teaching should constitute a large proportion of college teaching plan, and practical teaching should be designed and organized according to basic skills, professional skills and skills that students must master. It should also be noted that, with the development of economic society and technology, the training mode and calibre should not be the same as the requirement of the knowledge structure and capability level of higher vocational students. From cultivation program, teaching organization and management to the professional construction and reform of classroom teaching, examination, should be adjusted according to the needs of society in the quality of higher vocational colleges and improve, to achieve teaching with production and with the combination of student employment.

The development of the situation and competition need to cultivate innovative talents. Training innovation talents needs to innovate education. In the quality of classroom teaching assessment system is the need of cultivating innovative talents, is to strengthen macro management, improve the quality of teaching experiment, realize the important means of management by objectives, and necessary measures to solve the contempt of classroom teaching. At present, the assessment of classroom teaching in colleges and universities is mainly arranged in the assessment system of classroom teaching, and the teaching experiment is only one of the assessment items. Moreover, it is not conducive to the improvement of classroom teaching quality by evaluating the relative unitary and backward assessment of the system elements. Therefore, it is necessary to carry out classroom teaching quality evaluation system of research, discussion, establish the classroom teaching quality evaluation system of colleges and universities, and according to the actual circumstance of each school independently or together with the theoretical teaching in the classroom teaching evaluation system. To promote the development of teaching evaluation system has a very important role, and its outstanding performance in the following aspects: (1) the evaluation system about the direction of the construction and management of classroom teaching, has a guiding role, is advantageous to the national macro guidance and management of classroom teaching. (2) evaluation system to promote the sound and perfect classroom teaching the rules and regulations, with a specification, greatly promote the institutionalization of the management of classroom teaching work, scientific and standardized. (3) the evaluation system is conducive to improving the quality of classroom teaching, and the competition mechanism has attracted the classroom teaching and has an incentive effect. (4) the assessment system can scientifically estimate the development potential of classroom teaching, discover problems and deficiencies in time, have the diagnostic role, and promote the continuous search for innovation and development of classroom teaching. (5) the evaluation system is conducive to the acquisition of feedback information and the timely solution of the problem, which is the process of communication, mutual learning and mutual promotion between classroom teaching. It is beneficial for the classroom teaching to complement each other and achieve the highest goal.

The system structure of classroom teaching evaluation system index system is analyzed by systemically dynamic system thinking mode. The system principle and structure relation are revealed, and the system base mode is established

With system thinking method has the advantages of large analysis, it can always change numerous for brief integration question in detail, let us see things clearly behind the dynamic development of simple structure, see the crux of the problem. Applying this method to the 
assessment system will help us to get a foothold in the world, to get the focus, to work well and effectively to achieve our goals. Experimental system dynamic quality assessment system is the system dynamics and experimental evaluation system of system science and form the edge of the subject, the combination of experiment system dynamic quality assessment system to evaluate system as the research object, will be the research object is divided into several subsystems, and established between the factors and the causal relationship between each subsystem, determine the causal feedback loops, through system analysis, reasoning, and comprehensive, establishing computer simulation model of the system studied.

Through computer simulation, the intrinsic relationship between the structural function and dynamic behavior of the research system is analyzed and the countermeasures to solve the system problems are found out.

The evaluation system index system is an organic whole, and the impact of each index on the evaluation system results is different. In order to obtain scientific and accurate evaluation system results, the weights of indicators need to be determined. But the assessment system of certain parameters relationship is difficult to quantify or insufficient data is the study of problems frequently encountered a problem, however, under the condition of the system dynamics can still do some research work, this is because the structure of the system dynamics model is based on feedback loop, the existence of multiple feedback loop system behavior model is not sensitive to most parameters, in this way, although the lack of data, but as long as the estimated parameters within the tolerance, the system behavior is still showed the same pattern. By verifying the validity of the system model, the computer simulation is carried out to simulate various policies and measures, and the sensitivity analysis of the main factors affecting the development of the system is carried out. Through analysis and comparison, Suggestions for improving system structure are put forward to provide basis for formulating strategy and decision making.

\section{Conclusion}

In view of the characteristics of colleges and universities, and puts forward the modern classroom teaching quality evaluation software and remote assess the methods and measures of system platform, integrated application of these methods, certain achievements have been made in the teaching practice, the students' innovation ability and practice ability has the obvious enhancement, the spirit of the students' autonomous learning and ability are improved greatly. At the same time, it has also transformed some teachers' thinking of "retheory and light practice", so that they can combine their scientific research direction and how to improve students' practical ability. The practice platform construction is a system engineering, and many other links, such as open classroom teaching, course design, experimental project, etc. As long as we put these aspects of the work, to guarantee the necessary funds, set up the idea of take the student as the main body, can make the practice teaching on a new step, and implement personnel training target, strengthen the competitiveness of the talents in the society.

\section{Acknowledgements}

Fund Project: this thesis is the year 2016, the Education Department of Jiangxi province science and technology research project, project number: GJJ161156, the name of the project: "quality evaluation of modern classroom teaching software and remote evaluation system" series of research results based on stage.

\section{References}

[1] Wang Q F etc. The Influence of schedule Target on Project Performance, Journal of Fudan University, 2003,42(5):699-706

[2] SUN Yan-feng etc , A System Dynamics Approach For Sustainable Development in The MIYUN Reservoir Area, China, China Geographical Science, Beijing: Science press,2002 
[3] Jia Renan,etc A rate variable fundamental in-tree modeling and branch-vector approach to evaluating feedback loops, Proceedings of the ninetieth conference of the System Dynamics Society,ISBN 0-9672914-4-5,2001

[4] Jia Renan, A Case of Energy and Ecology System Development and a New Approach to System Dynamics Modellings Systems Science andSystem Engineering ,2002,11(4)

[5] Ren Wei-qun ,etc A New Application of Multi-Body System Dynamics in Vehicle-Road Interaction Simulation ,WUJNS,2003

[6]Research and practice of classroom teaching quality assessment system system [J], journal of jiangsu technical normal university, 2003, 9 (2) : 75-78 